N. CHIDA, M. OHTUSKA, K. NAKAZAWA, S. OGAWA* (KEIO UNIVERSITY, YOKOHAMA, JAPAN )

Total Synthesis of Antibiotic Hygromycin A

J. Org. Chem. 1991, 56, 2976-2983, DOI: 10.1021/jo00009a009.

\section{Hygromycin A Finds a New Purpose}
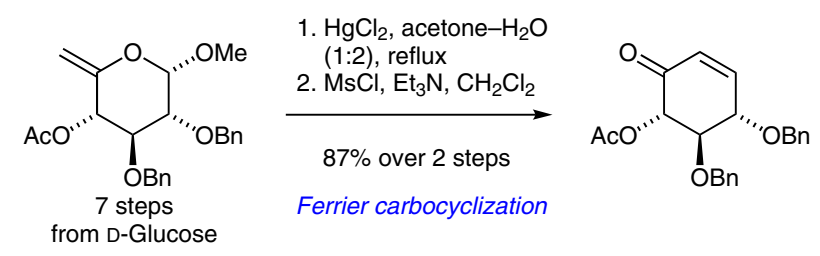
1. $\mathrm{NaBH}_{4}, \mathrm{CeCl}_{3} \cdot 7 \mathrm{H}_{2} \mathrm{O}$,
$\mathrm{MeOH}, 0^{\circ} \mathrm{C}$
2. dihydropyran, PPTS
$85 \%$ over 2 steps

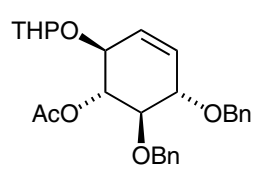

Ferrier carbocyclization
Category

Chemistry in

Medicine and

Biology

\section{Key words}

\section{Ferrier}

carbocyclization

Wittig reaction

Sharpless

dihydroxylation

drug repurposing
1. $\mathrm{NaOMe}, \mathrm{MeOH}$
2. $\mathrm{MsCl}$, pyridine, $50^{\circ} \mathrm{C}$
3. $\mathrm{NaN}_{3}, \mathrm{HMPA}, 100^{\circ} \mathrm{C}$

$26 \%$ over 3 steps

1. $\mathrm{NaH}, \mathrm{CH}_{2} \mathrm{Br}_{2}$, DMF

2. $\mathrm{H}_{2}, \mathrm{Pd}(\mathrm{OH})_{2}$

3. TFA

$40 \%$ over 3 steps
1. $\mathrm{LiAlH}_{4}$ then $\mathrm{Boc}_{2} \mathrm{O}$

2. $\mathrm{OsO}_{4}$ (0.12 equiv), $\mathrm{NMO}$

(1.5 equiv), hydroquinine 4-chlorobenzoate ( 0.15 equiv)<smiles>[B][C@H]1C=C[C@H](O)[C@@H](N)[C@H]1OCc1ccccc1</smiles>

$69 \%$ over 2 steps Sharpless dihydroxylation

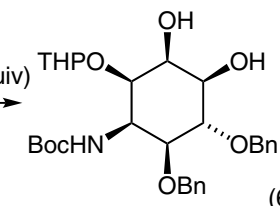

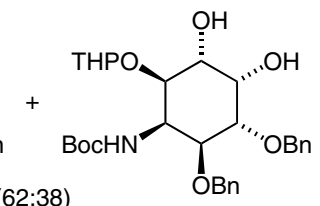
$(62: 38)$<smiles>N[C@H]1[C@@H](O)[C@H](O)[C@H](O)[C@@H]2OCO[C@@H]21</smiles><smiles>CC(=O)Oc1cc(C)ccc1O[C@@H]1O[C@H](C(C)=O)[C@@H](OC(C)=O)[C@H]1OC(C)=O</smiles><smiles>CCO[N+](C)(C)O[Na]</smiles><smiles>COC1C(Oc2ccc(C=O)cc2[O-])OC(C(=O)O)C1OC(C)=O</smiles>

1. $\mathrm{Ph}_{3} \mathrm{P}=\mathrm{C}(\mathrm{Me}) \mathrm{CO}_{2} \mathrm{Et}$ 2. $1 \mathrm{M} \mathrm{NaOH}, \mathrm{MeOH}, 50^{\circ} \mathrm{C}$ 3. $\mathrm{Ac}_{2} \mathrm{O}$, pyridine

$66 \%$ over 3 steps Wittig reaction<smiles>C/C(=C\c1ccc(OC2OC(C(=O)O)C(O)C2O)c([N+](=O)[O-])c1)C(=O)O</smiles>

1. A, $(\mathrm{EtO})_{2} \mathrm{P}(\mathrm{O}) \mathrm{CN}, \mathrm{Et}_{3} \mathrm{~N}, \mathrm{DMF}$

2. $\mathrm{Ac}_{2} \mathrm{O}$, pyridine

3. $\mathrm{NaOMe}$ then TFA

$32 \%$ over 3 steps

Yamada peptide coupling

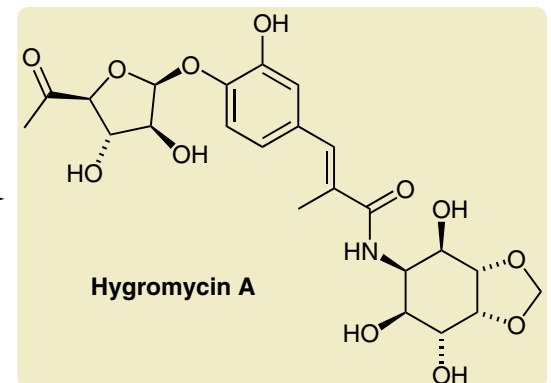

Significance: Hygromycin A is a broad-spectrum antibiotic produced by Streptomyces. It was recently rediscovered as a potential therapy for the treatment of Lyme Disease (Cell 2021, 184, 5405). In mouse models, Hygromycin A was active against $B$. burgdorferi without disturbing the microbiome.
Comment: The first total synthesis of Hygromycin A was reported by Ogawa and co-workers in 1991. Key transformations included a Ferrier carbocyclization and a Sharpless dihydroxylation to form building block A. The furanose and aminocyclitol fragments were pieced together using a Wittig reaction followed by a Yamada peptide coupling. 